\title{
Astatinated trastuzumab, a putative agent for radionuclide immunotherapy of ErbB2-expressing tumours
}

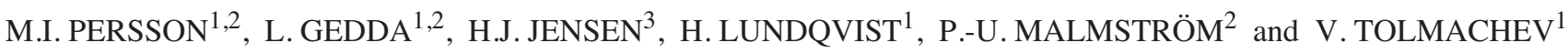 \\ ${ }^{1}$ Unit of Biomedical Radiation Science, Department of Oncology, Radiology and Clinical Immunology; \\ ${ }^{2}$ Unit of Experimental Urology, Department of Surgical Sciences, Uppsala University, S-751 85, Uppsala, Sweden; \\ ${ }^{3}$ PET and Cyclotron Unit, Department of Clinical Physiology and Nuclear Medicine, \\ Righshospitalet, Blegdamsvej 9, 2100 København Ø, Copenhagen, Denmark
}

Received September 6, 2005; Accepted November 10, 2005

\begin{abstract}
The anti-ErbB2 antibody trastuzumab is used for the treatment of patients with advanced breast cancer, resulting in a response rate of 40-60\%. Coupling with a cytotoxic nuclide, e.g. $\alpha$-emitting ${ }^{211} \mathrm{At}$, may further increase tumour response. The tumour-targeting properties of trastuzumab, astatinated using $N$-succinimidyl-para-(tri-nmethylstannyl)-benzoate, were evaluated and compared with those of radioiodinated trastuzumab in this study. We found that astatinated trastuzumab retains high specificity towards ErbB2. While the immunoreactive fraction of radioiodinated trastuzumab was higher than that of astatinated trastuzumab (76 $\pm 9 \%$ versus $54 \pm 28 \%$ ), both radioconjugates showed high affinity $\left(\mathrm{K}_{\mathrm{D}} 0.75 \pm 0.16 \mathrm{nM}\right.$ versus $\left.1.8 \pm 0.3 \mathrm{nM}\right)$. A growth inhibition study indicated a dose-dependent cell deactivation, in which approximately 74 cell-associated astatine decays per cell gave a survival fraction of $4.5 \pm 0.8 \times 10^{-4}$. Results of a comparative animal study on normal mice gave no indication that astatination would have any adverse effects on the biodistribution of the antibody. In conclusion, the results of the study suggest that astatinated trastuzumab is a promising candidate for treating ErbB2-expressing tumours.
\end{abstract}

\section{Introduction}

Approximately $20 \%$ of fatalities in the population of industrialised countries can be attributed to cancer, which makes it the second largest cause of death after cardiac diseases (1). Many tumours are treatable with contemporary methods, mainly surgery and external radiation therapy.

Correspondence to: Dr Mikael Persson, Unit of Biomedical Radiation Sciences, Rudbeck laboratory, Uppsala University, S-751 85 Uppsala, Sweden

E-mail: mikael.persson@bms.uu.se

Key words: cancer, astatine, ErbB-2, targeting, radioimmunotherapy
However, these methods are unsuitable for micrometastases and disseminated single cells, which are not detectable due to their small size. A systemic treatment is required for the eradication of this type of spread disease, and such treatment needs to be highly selective to minimise damage to healthy organs and tissue. One possible approach could be targeting, a delivery of cytotoxic agents based on molecular recognition of cellular structures specific for or overexpressed in tumour cells. Monoclonal antibodies are often considered targeting vectors, especially when coupled with radionuclides or cytotoxic drugs (2).

A potential target is ErbB2 (HER-2/neu), which is a transmembrane protein belonging to the human epidermal growth factor tyrosine kinase receptor family. Increased ErbB2 activity is associated with increased proliferation and decreased apoptotic activity $(3,4)$. ErbB2 is often overexpressed in a number of different tumours, i.e. breast, ovarian, and urinary bladder (3), but is expressed in normal adult tissues only to a small extent $(5,6)$. The overexpression of ErbB2 is associated with short symptom-free survival (7), and often preserved in metastases (8). These factors together are strong arguments for a strategy targeting ErbB2.

Trastuzumab, a humanized anti-ErbB2 monoclonal antibody and active ingredient of the Herceptin ${ }^{\circledR}$ pharmaceutical, is widely used in a clinical setting and often in combination with chemotherapy (9-11). Trastuzumab targets a cysteinerich part of the extracellular domain of ErbB2 close to the transmembrane region and is thought to cause homodimerisation and internalisation of ErbB2, especially when the protein is overexpressed (12). The response rate to Herceptin therapy varies between $40 \%$ and $60 \%$, and coupling a cytotoxic nuclide to trastuzumab might further increase this response rate. It has been shown that ${ }^{90} \mathrm{Y}$-labeled anti-lymphoma antibody Zevalin is efficient against tumours, which are resistant to its non-conjugated counterpart Rituximab (13).

For radionuclide targeting of single disseminated cells and micrometastases, use of an $\alpha$-emitter is among the more promising approaches. Due to their short range, $\alpha$-particles deposit all of their energy within a few cell diameters from the location of decay, thus sparing surrounding healthy tissues. The high linear energy transfer (LET) of $\alpha$-particles also gives an almost optimal average distance between 
ionising events. At $100 \mathrm{keV} / \mu \mathrm{m}$, the typical LET value for emitted $\alpha$-particles, the distance is about the same as the distance between DNA strands, thus highly increasing the probability of a double-strand break (14). A number of $\alpha$-emitters were considered for therapy, but only ${ }^{212} \mathrm{Bi}\left(\mathrm{T}_{1 / 2}=\right.$ $60 \mathrm{~min}),{ }^{213} \mathrm{Bi}\left(\mathrm{T}_{1 / 2}=45 \mathrm{~min}\right)$ and ${ }^{211} \mathrm{At}\left(\mathrm{T}_{1 / 2}=7.2 \mathrm{~h}\right)$ can be produced in an economically reasonable way (15). Among those, only ${ }^{211}$ At has a half-life long enough to be considered for the targeting of solid tumours using an intact antibody as the targeting vehicle. ${ }^{211}$ At produces one $\alpha$-particle in every possible decay pathway. The mean LET of these particles is $97 \mathrm{keV} / \mu \mathrm{m}$, which is close to the optimal value (14). Since we are not aware of any published data on radiolabelled trastuzumab, a basic characterisation of the conjugated targeting agent is needed to assess the effect of labelling this specific antibody.

The goal of this study was to evaluate the tumour-targeting properties of astatinated trastuzumab. We have coupled ${ }^{211} \mathrm{At}$ to the antibody via the linker molecule $N$-succinimidyl-para(tri-n-methylstannyl) benzoate (SPMB), a variant of the para-trialkyltin-phenyl compounds suggested by Wilbur et al (16). A pre-clinical characterisation of this targeting complex, including issues of binding, specificity, cellular processing, immunoreactive fraction, affinity, and the results of in vitro experimental therapy and an in vivo biodistribution study in NMRI mice, is reported.

\section{Materials and methods}

Cell line. The ErbB2-overexpressing breast carcinoma cell line, SK-BR-3, was obtained from ATCC and grown in HAM's F-10 media, complemented with $10 \%$ (v/v) foetal bovine serum, $2 \mathrm{mM}$ L-glutamine, and $100 \mu \mathrm{g} / \mathrm{ml}$ penicillin/ streptavidin (all from Biochrome, Berlin), henceforth referred to as complete media.

Chemicals. Trastuzumab (Herceptin; Genentech, San Francisco, CA) was obtained from a local pharmacy and purified from salts and amino acids by size exclusion chromatography on a PD-10 ${ }^{\mathrm{TM}}$ column (Amersham Biosciences, Uppsala, Sweden). In the labelling reactions, Chloramine-T (Merck, Darmstadt, Germany) and sodium metabisulfite (Aldrich, Steinheim, Germany) were used together with SPMB, which was synthesized in our laboratories according to the protocol of Koziorowski et al (17).

Astatine-211 was produced via the ${ }^{209} \mathrm{Bi}(\alpha, 2 \mathrm{n}){ }^{211}$ At nuclear reaction. Targets were prepared by evaporating a layer of $18-20 \mathrm{mg} / \mathrm{cm}^{2} 99.999 \%$ pure ${ }^{209} \mathrm{Bi}$ metal onto $30 \times 28 \times 5 \mathrm{~mm}$ aluminium backings at the Department of Physics, Chalmers University of Technology, Gothenburg, Sweden. An additional layer of aluminium, $1 \mathrm{mg} / \mathrm{cm}^{2}$, was added on top of the target to prevent diffusion and evaporation of ${ }^{211}$ At during irradiation. The targets were irradiated at the Copenhagen University Hospital, Copenhagen, Denmark, using a Scanditronix MC32 Cyclotron. The $\alpha$-beam was adjusted to give an entrance energy of approximately $28 \mathrm{MeV}$ at the ${ }^{209} \mathrm{Bi}$ layer during all productions. With a beam energy of $18 \mu \mathrm{A}$ and an irradiation time of $4 \mathrm{~h}$, activities of typically $1 \mathrm{GBq}{ }^{211} \mathrm{At}$ were produced by the end of the bombardment. After delivery to Uppsala University, astatine was separated from the target material by dry distillation, as described by Sjöström et al (18), and recovered as a solution in $200 \mathrm{ml}$ methylene chloride. Control experiments were performed with an iodine-125 label (Amersham Biosciences).

Instruments. An automated $\gamma$-counter with a 3-inch $\mathrm{NaI}(\mathrm{Tl})$ detector (1480 Wallac Wizard, Perking-Elmer, Wellesley, MA) was used. To obtain absolute values of cell-associated radioactivity, the $\gamma$-counter was calibrated using astatine samples with known activity. The activity of these samples was measured using an ultra-pure germanium detector (ORTEC) with a multichannel analyser (The Nucleus, Inc., Oak Ridge, TN) working online with a PC. The detector was calibrated for energy and efficiency with a ${ }^{152} \mathrm{Eu}$ standard source. The $\gamma$-ray energy and abundance were taken from the Table of Isotopes (19).

Cells were counted using an electronic cell counter (Beckman-Coulter, Fullerton, CA). Size exclusion chromatography was performed using disposable NAP- $5^{\mathrm{TM}}$ columns (Amersham Biosciences).

Labelling procedure. For the labelling of trastuzumab, a 'onepot' labelling in aqueous media was used. Methylene chloride was evaporated with a gentle stream of argon gas, and astatine was re-solubilised in $10 \mu 10.01 \mathrm{M}$ acetic acid in water. SPMB $(3-5 \mu \mathrm{g} ; 1 \mathrm{mg} / \mathrm{ml}$ in $5 \%$ acetic acid in methanol) was mixed with the astatine solution. The reaction was started by adding Chloramine-T (30 $\mu \mathrm{g}, 3 \mathrm{mg} / \mathrm{ml}$ in water), left for $5 \mathrm{~min}$ and then terminated by adding sodium metabisulphite $(80 \mu \mathrm{g}$; $6 \mathrm{mg} / \mathrm{ml}$ in water). Trastuzumab $(300 \mu \mathrm{g}, 10 \mathrm{mg} / \mathrm{ml}$ in $0.07 \mathrm{M}$ borate buffer, $\mathrm{pH}$ 9.1) was added to the reaction mixture, and the coupling reaction proceeded for $30 \mathrm{~min}$ at room temperature with continuous shaking. The labelled antibody was then separated from reagents by size-exclusion chromatography on an NAP-5 column. An overall yield of 45-60\% was typically obtained. Radioiodination of the antibody for comparative studies was performed in a similar way with a typical overall yield of $40-70 \%$.

Cellular accumulation and retention. SK-BR-3 cells were seeded in $\varnothing 35 \mathrm{~mm}$ Nunc $\Delta$-surface cell dishes (Nunc, Roskilde, Denmark) and grown for 3 to 4 days, until they reached an approximate number of 200,000 cells/dish. The cells were then washed once with complete media before the start of the experiments.

Cellular accumulation was studied by adding $1 \mathrm{ml} 0.65 \mathrm{nM}$ radiolabelled antibody in complete media. To determine binding specificity, receptors were blocked in half of the samples by adding a 1,000 times molar excess of non-labelled trastuzumab. The dishes were then incubated at $37^{\circ} \mathrm{C}$ in $5 \%$ $\mathrm{CO}_{2}$, and cells were harvested at $0.5,1,2,4,7,14$, and $21 \mathrm{~h}$ as follows. The incubation media was collected for radioactivity measurement, and dishes were washed 6 times with serum-free media before $500 \mu 1$ trypsine-EDTA solution (Biochrome, Berlin, Germany) was added. This was followed by incubation at $37^{\circ} \mathrm{C}$ for $10 \mathrm{~min}$, after which $1 \mathrm{ml}$ complete media was added to inactivate the trypsine. A sample of $0.5 \mathrm{ml}$ cell solution was then taken for cell counting, and the remaining solution $(1 \mathrm{ml})$ was collected for radioactivity measurement. 
Cellular retention was studied by first incubating the cells for $4 \mathrm{~h}$ in $1 \mathrm{ml}$ complete media containing $0.65 \mathrm{nM}$ radiolabelled antibody. The incubation media was then collected for radioactivity measurement. The cells were washed 6 times in serum-free media, and three zero-point samples were harvested. The remainder were given fresh complete media and left to incubate for $1,2,4,8$, and $20 \mathrm{~h}$ before being harvested. Cells were harvested using the acid wash method to discriminate between internalised and membrane-bound radioactivity (20). Briefly, the cells were incubated in $0.5 \mathrm{ml}$ $0.1 \mathrm{M} \mathrm{HCl}$ on ice for $6 \mathrm{~min}$. The acid was then collected, and the cells were washed again with ice-cold acid, which was collected together with the first acid. The radioactivity in these fractions was considered membrane-bound. After this, $0.5 \mathrm{ml}$ of $1 \mathrm{M} \mathrm{NaOH}$ was added, and the cells were incubated at $37^{\circ} \mathrm{C}$ for $1 \mathrm{~h}$ to dissolve all cells before the fluid was collected. The dishes were then washed with $0.5 \mathrm{ml} \mathrm{NaOH}$ that was collected together with the first $\mathrm{NaOH}$. The radioactivity in these fractions was considered to be internalised.

Immunoreactive fraction. The fraction of antibody that was still reactive was estimated using a modified version of the protocol developed by Lindmo et al (21). Briefly, cells were detached from the culture flask surface by scraping, then counted in a Coulter Z2 cell counter. Cells were added to 24 Eppendorf tubes in four decreasing concentrations. The amount of labelled trastuzumab never exceeded $10 \%$ the amount of ErbB2, and the experiment was performed at $4^{\circ} \mathrm{C}$ to minimize internalisation. The cells were centrifuged at $2,550 \mathrm{x} \mathrm{g}$, and the media was removed. Half of the samples received $500 \mu \mathrm{l}$ of complete media, and the other half received the same amount of complete media with added non-labelled trastuzumab $(240 \mu \mathrm{g} / \mathrm{ml})$, the cells were resuspended and then incubated for $30 \mathrm{~min}$ to allow the non-labelled antibody to block the receptors before $500 \mu \mathrm{l}$ complete media with labelled trastuzumab $(24 \mu \mathrm{g} / \mathrm{ml})$ were added to all tubes, and the samples were left to incubate for $4 \mathrm{~h}$. The cells were then centrifuged at 2,550 x g a second time, and the media was collected for $\gamma$-counter analysis. Complete media $(1 \mathrm{ml})$ was added, and the cells were again resuspended and centrifuged. The media was removed and a further $1 \mathrm{ml}$ of complete media was added without disturbing the pellet. A short centrifugation was performed, the final media was removed, and the cell-associated radioactivity was measured in a $\gamma$-counter.

Affinity measurements. Cells were seeded in 24-well plates with a density of 10,000-20,000 cells/well and grown in complete media for 4-5 days before the experiment. The cells were washed once with complete media before the start of the experiment. A dilution series of labelled antibody in complete media of 1000:1-1:1 antibody/receptor ratio was made, based on the assumption of $2 \times 10^{6}$ receptors/cell and 20,000 cells/well. Complete media with a 100 -fold excess of non-labelled antibody was also prepared to assess specific binding of the antibodies. Complete media $(1 \mathrm{ml})$ with the appropriate antibody concentration was added to each well, while the plates were kept on ice. All samples were made in triplicate. After the media was added, the samples were left to incubate for at least $16 \mathrm{~h}$ on ice before the cells were harvested. The incubation media was collected for later analysis on a $\gamma$-counter. The cells were then washed 6 times with ice-cold serum-free HAM's F-10 media before $500 \mu 1$ trypsine was added to each well. After at least $10 \mathrm{~min}$ incubation in $37^{\circ} \mathrm{C}, 1 \mathrm{ml}$ of complete media was added, and the cells were resuspended for single cell suspension. A 1-ml cell suspension was then collected for radioactivity measurement. A subset of cell suspensions was analysed in a Coulter Z2 cell counter to obtain the average cell density of the samples.

Determination of cell survival by growth inhibition. The growth inhibition method, originally used for cells growing in suspension, was used due to the poor and density-dependent plating efficiency of SK-BR-3 cells. This method has been described for use in monolayers (22), and verified to give results comparable with the clonogenic survival assay (22-24). Cells were grown in monolayers in $\varnothing 35 \mathrm{~mm}$ Nunc $\Delta$-surface cell culture dishes. At the start of the experiment, the cells were washed once with complete media, and between 2.5 to $0.25 \mathrm{nM}$ astatinated trastuzumab in $1 \mathrm{ml}$ complete media was added to appropriate dishes (control experiments are described at the end of the paragraph). The dishes were left to incubate in $37^{\circ} \mathrm{C}, 5 \% \mathrm{CO}_{2}$ for $24 \mathrm{~h}$ before the media was removed. The cells were then washed 6 more times with complete media before new media was added. During this time, sample dishes were harvested at 1, 2, 4, 8, 16, and $24 \mathrm{~h}$. The incubation media was removed for radioactivity measurement, and the cells were washed 6 times in serumfree media before being trypsinised and counted in a Coulter Z1 cell counter, and the cell-associated radioactivity was measured.

The remaining unharvested cell dishes were counted and subcloned into Nunc $\Delta$-surface cell culture flasks on day 3 , and repeatedly subcloned and counted at appropriate times. Subcloning was aimed at seeding cells at a density of 250,000 cells per flask, but the growth curve was calculated as if all cells had been saved.

Specificity of the treatment was demonstrated using three sets of controls. In the first control set, used to detect any possible effect of non-labelled antibody on cell survival, no astatinated antibody was added. Instead, an amount of nonlabelled antibody equal to the concentration of the labelled trastuzumab was added. In the second set of controls, binding of the astatinated antibody (in an amount corresponding to the highest sample dose) was blocked by the addition of a 1,000-fold molar excess of non-labelled antibody. These controls were used to estimate the impact of radioactivity in the media. To the third set of controls, no antibody was added. This set was used to estimate influence of cell handling on their survival. All controls and samples were made in triplicate.

Biodistribution. A total of 20 female NMRI mice (Taconic M\&B A/S, Ry, Denmark) were injected with a $30 \mu \mathrm{l}$ cocktail of radioiodinated $(1 \mu \mathrm{M})$, and astatinated trastuzumab $(1 \mu \mathrm{M})$ via the tail vein. Four mice were sacrificed at 1, 3.5, 7, 14 and $21 \mathrm{~h}$ post-injection using an overdose of anaesthesia followed by heart puncture and removal of blood. Blood and organs were harvested and weighed, and their radioactivity was measured in a $\gamma$-counter. The percentage of injected dose per gram in the different organs was calculated using a set of 

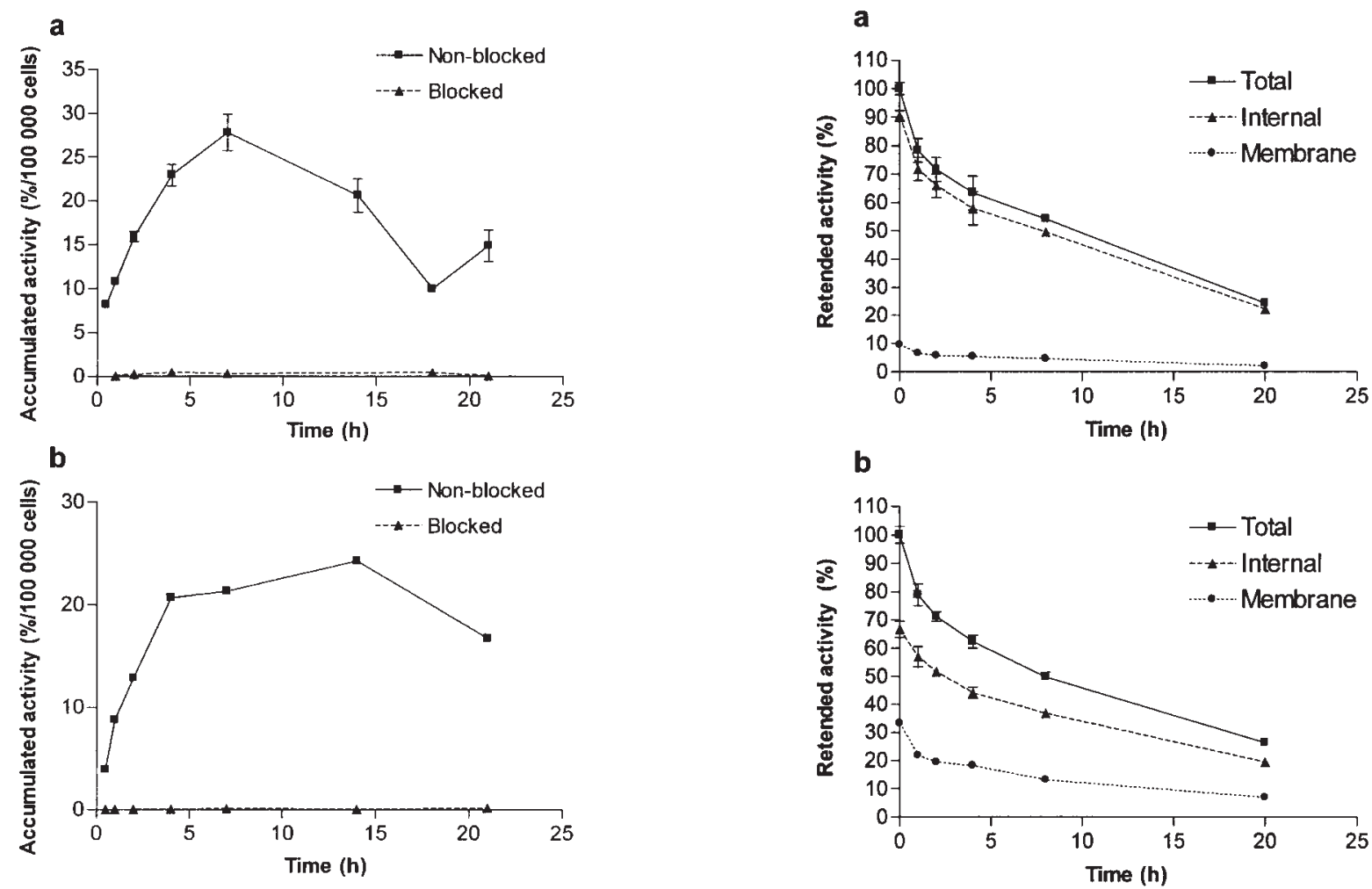

Figure 1. Cellular accumulation of radiolabelled trastuzumab. The plots show the accumulation of SK-BR-3 cells associated radioactivity from media (the rate of antibody to receptor was approximately 1:1). The plots show results from (a) a radioiodinated and (b) an astatinated antibody.

standards taken out at injection time as the injected dose. The astatine data were then further compensated for decay during measurements between, but not within, each set of animal organs.

Data treatment. Cellular accumulation and retention together with in vivo biodistribution data were processed with Microsoft Excel 2000 (Microsoft, Redmond, WA) and are presented as averages with minimum-maximum error bars. Data from the immunoreactive fraction, affinity measurements and cell survival were analysed with GraphPad Prism (GraphPad Software, San Diego, CA), using built-in non-linear and linear regression. Regression was calculated with the stricter convergence criteria set. Values are presented as averages with error bars showing standard errors.

\section{Results}

Cellular accumulation and retention. Fig. 1 describes the binding pattern of trastuzumab to SK-BR-3 cells. The uptake of radioactivity was shown to be highly ErbB2-specific, since it can be suppressed by blocking the binding sites using a large amount of non-labelled mAb. Unspecific binding was never higher than $0.48 \% / 100,000$ cells for iodine-labelled $\mathrm{mAb}$ or $0.12 \% / 100,000$ cells for astatine-labelled $\mathrm{mAb}$. The binding reached a maximum of ${ }^{125} \mathrm{I}(28 \% / 100,000$ cells) after $7 \mathrm{~h}$, and ${ }^{211} \mathrm{At}(24 \% / 100,000$ cells) after $14 \mathrm{~h}$, then decreased to around $15 \%$ of added radioactivity per 100,000 cells after $21 \mathrm{~h}$. The total retention pattern was the same with both compounds, but the astatinated antibody was located on

Figure 2. Cellular retention of radiolabeled trastuzumab. The plots show results from (a) a radioiodinated and (b) an astatinated antibody.
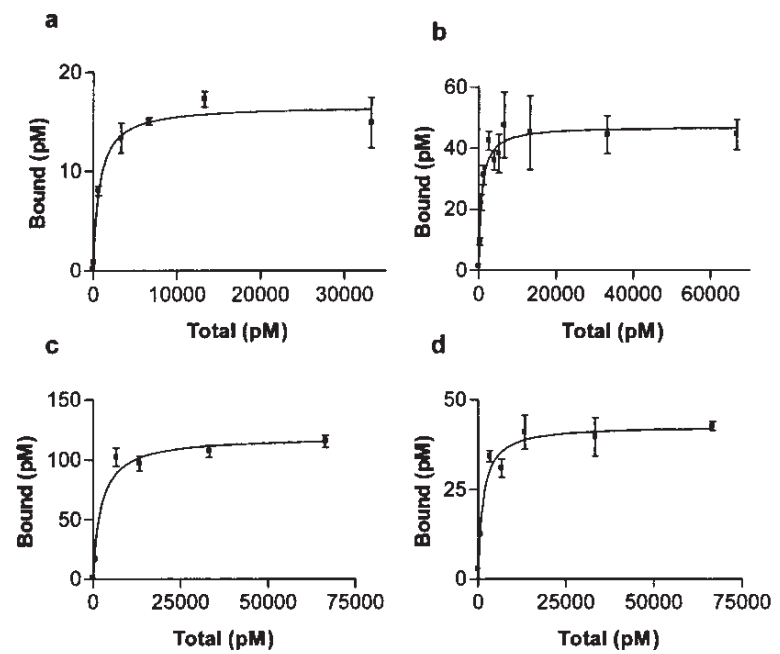

Figure 3. Receptor saturation curves of different affinity measurements. Plots (a) and (b) depict two experiments using radioiodinated trastuzumab, and plots (c) and (d) depict two experiments using astatinated trastuzumab. $\mathrm{K}_{\mathrm{D}}$ calculated from the experiments were (a) $0.72 \pm 0.21 \mathrm{nM}$; (b) $0.78 \pm 0.25 \mathrm{nM}$; (c) $2.3 \pm 0.6 \mathrm{nM}$; and (d) $1.4 \pm 0.4 \mathrm{nM}$, respectively.

the membrane of cells to a higher degree, although the internalised fraction was still larger than the membranebound fraction (Fig. 2). The total retention of iodinated and astatinated antibody after $20 \mathrm{~h}$ was $24.3 \pm 0.7 \%$ and $26.4 \pm 0.6 \%$, respectively of initially cell-associated radioactivity.

Immunoreactive fraction. The experiment plots suggested an immunoreactive fraction (percent of antibody that would 

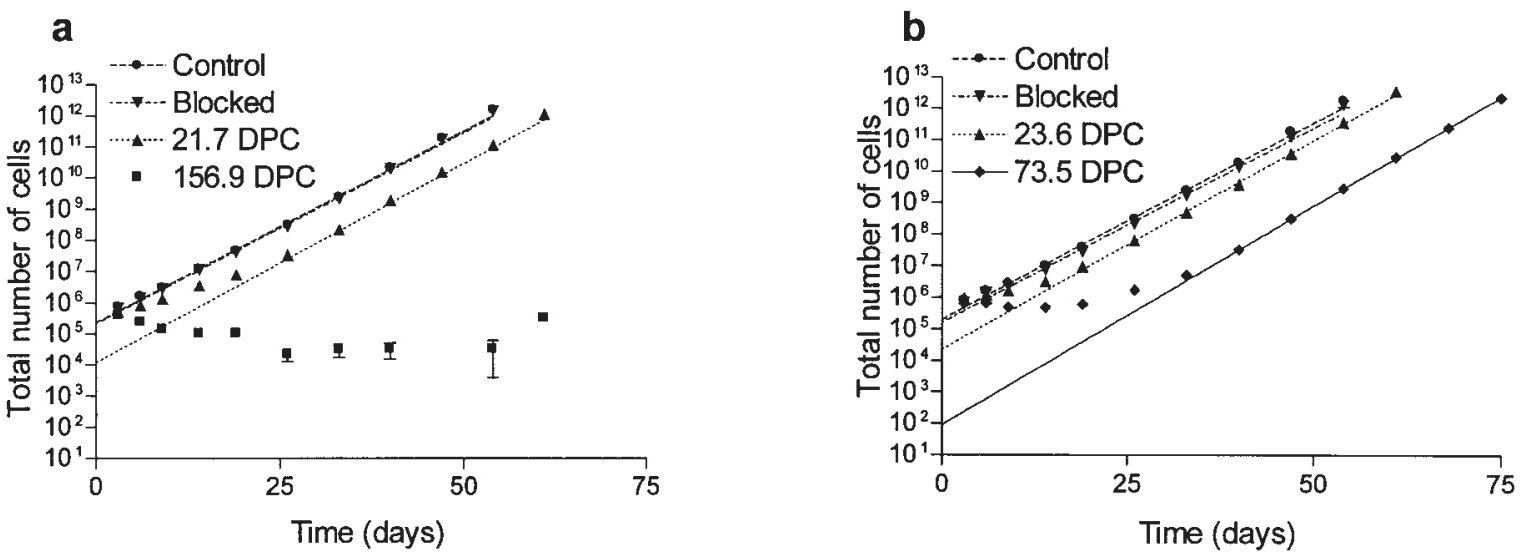

Figure 4. Growth curves of SK-BR-3 cells with different levels of irradiation by astatinated trastuzumab. In (a) and (b), the dotted lines represent the rate of the exponential phase of growth of the 21 and 23 DPC samples, respectively. In (b), the solid line represents the same for growth of the 80 decays per cell (DPC) samples. Dashed and dash-dotted lines at the top represent the exponential growth of blocked and control samples. In both charts, error bars represent standard deviation. When the lower error bar or a whole point is missing, it represents a negative value.

Table I. Surviving fraction of different irradiations and doubling time of exponential growth.

\begin{tabular}{lcccr}
\hline Dose & Surviving fraction & SE & Doubling time & SE \\
\hline Control & 1 & N/A & 2.5 days & 0.03 days \\
$21.7 \mathrm{DPC}$ & $5.19 \times 10^{-2}$ & $1.93 \times 10^{-2}$ & 2.4 days & 0.06 days \\
$23.6 \mathrm{DPC}$ & $1.11 \times 10^{-1}$ & $2.18 \times 10^{-2}$ & 2.3 days & 0.03 days \\
$73.5 \mathrm{DPC}$ & $4.45 \times 10^{-4}$ & $7.66 \times 10^{-5}$ & 2.2 days & 0.02 days \\
$156.9 \mathrm{DPC}$ & N/A & N/A & 6.4 days & 0.17 days \\
\hline
\end{tabular}

bind at infinite antigen excess) of $75.7 \pm 8.6 \%$ and $54 \pm 28 \%$ for the radioiodinated and astatinated antibody, respectively.

Affinity measurements. Results of affinity measurements are graphically presented in Fig. 3. Data concerning iodinated trastuzumab are in good agreement. Data for astatinated trastuzumab differ somewhat, which can probably be attributed to the variation of specific activity at the start of the experiment. Average $\mathrm{K}_{\mathrm{D}}$ values calculated from these curves were $0.75 \pm 0.16 \mathrm{nM}$ for radioiodinated antibody and $1.8 \pm 0.3 \mathrm{nM}$ for astatinated antibody (Fig. 3). The overall amount of receptors per cell was estimated to $2.15 \pm 0.05 \times 10^{6}$ receptors/ cell, corresponding well to previously published data (25).

Determination of cell survival by growth inhibition. All cells treated with antibody (labelled or non-labelled) showed growth inhibition during the time of antibody treatment (data not shown). However, only the cells treated with labelled antibody showed any growth inhibition once the media containing antibodies had been removed. These cells showed growth inhibition in a dose-dependent manner (Fig. 4). The cells that received the highest radiation dose actually decreased in number during the first month, until there were so few that the amount went below the detection threshold of the cell counter. At this point, microscopic inspection revealed only a few single cells in one sample. However, variations in background due to bubbles forming during the resuspension of cells, together with multiplication factors due to subcloning, combined to cause the average cell number stay around $10,000 / \mathrm{ml}$ in triplicate experiments, as determined by cell counter measurement. Despite this, 1 or 2 samples at each data point generally showed a zero or negative amount of cells (note missing data point in Fig. 4a due to a negative average amount of cells). After 2 months, the regrowth of cells was visible upon inspection with a microscope in 2 of 3 samples, and this regrowth could be detected by cell counting after 4 months. The third sample never showed any remaining cells. The doubling time for regrowing cells was longer than that for normal cells, and therefore no extrapolation of the initial cell number could be made. The implications of this abnormality are covered in the Discussion. Extrapolation of normal growth rates suggests surviving fractions, as shown in Table I.

Biodistribution. Results of the biodistribution studies presented in Fig. 5 indicate no major adverse effect of astatination. Biodistributions of the astatinated and radioiodinated antibody closely resemble one another. Organs with the highest uptake of both labels were the spleen and liver, and the only organs where a significant difference was observed between the two labels were the thyroid and stomach.

\section{Discussion}

A large proportion of fatalities from cancer are due to metastatic growth, even when the primary tumours have been surgically removed. Suppression of metastatic growth would provide patients with a longer symptom-free life, but such treatment needs to be specific in order to not further harm healthy cells. Targeting $\alpha$-emitters such as ${ }^{211}$ At may help, since the main 


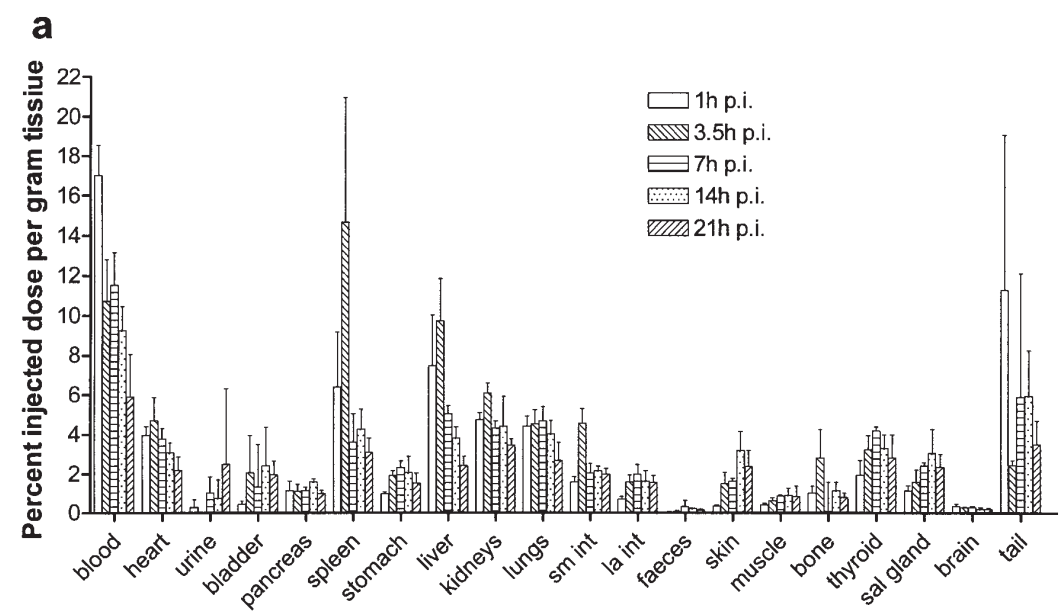

b

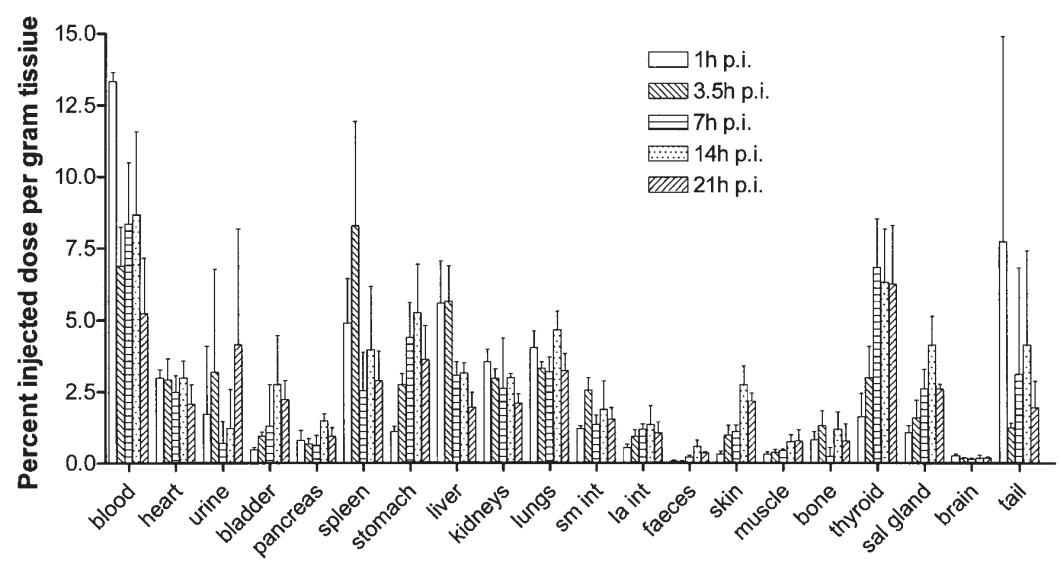

Figure 5. Biodistribution of radiolabelled antibody in NMRI mice. Graphs show the percentage of injected dose per gram in collected tissue at $1,3.5,7,14$ and $21 \mathrm{~h}$ post-injection. Graph (a) shows radioiodinated antibody, and graph (b) astatinated antibody.

radiation dose they deliver is concentrated in a small volume around the targeting agent. It is important, however, that the targeting ability of the antibody is not affected by the chemical modifications associated with labelling, as well as other factors, e.g. radiolysis. Indirect astatination of antibodies using succinimidyl ester of para-astatobenzoate is a wellestablished procedure, which usually produces a labelled antibody with preserved immunoreactivity $(26,27)$. Such labelling modifies lysine residues, and its safety should be demonstrated for each antibody. The labelling procedure was modified in this study with the aim of performing the whole process in aqueous media, which could also affect the antibody.

The cellular accumulation and retention experiments show that the astatinated trastuzumab retained its capability to bind ErbB2 expressing cells with high specificity. The affinity of astatinated antibodies, though lower than that of iodinated ones, was still in the low nanomolar range thus ensuring efficient targeting. For comparison, coupling the DOTA chelator with the murine counterpart of trastuzumab, 4D5, lowers affinity to $12.5 \mathrm{nM}$. Yet, ${ }^{90} \mathrm{Y}$-labeled 4D5 reduces tumour growth in a mouse xenograft model (28). De Santes and co-workers have reported a $\mathrm{K}_{\mathrm{D}}$ value of $1.55 \mathrm{nM}$ for radioiodinated 4D5 using the Iodo-Gen method (29). Again, treatment with ${ }^{131} \mathrm{I}-4 \mathrm{D} 5$ caused a marked inhibition of tumour xenograft growth in the cited study. We can suppose that the labelling method provides an affinity that is adequate for radionuclide tumour targeting. The lower immunoreactive fraction and affinity of astatinated trastuzumab, in comparison with its iodinated counterpart, may be caused by radiolysis. It has been demonstrated that radiolysis during labelling causes a decrease in immunoreactivity (30). Protection against radiolysis should be carefully addressed in future studies. We hope that the valuable experience of other researchers who developed radioimmunoconjugates labelled with short-lived bismuth isotopes can be utilised (31).

Comparative experiments on cellular retention demonstrated similar patterns for overall cell-associated radioactivity for radioiodinated and astatinated trastuzumab. However, the results of the acid wash showed that a larger fraction of radioiodinated trastuzumab was internalised. Astatination, for some reason, may slow down internalisation of trastuzumab or it is also possible that the difference may represent errors in the method used. The acid wash is an accepted method for the discrimination of internalised and membrane-bound antibodies (32), but errors cannot be excluded as it may fail to remove some membrane-bound antibodies due to the high affinity of their binding. Should this occur, radioactivity of the internalised fraction would be overestimated. As a control, the acid wash method was verified for its ability to discriminate between internalised and membrane-bound radioiodinated trastuzumab on ice. It was found that some radioactivity, although less than in $37^{\circ} \mathrm{C}$, was determined as internalised despite incubation on ice (data not shown). 
In addition to having a high specificity, the metastasiscontrolling agent must be highly cytotoxic, so only a small number of molecules need to be delivered to the tumour cells for efficient cell deactivation. In theory, the high LET of $\alpha-$ particles makes $\alpha$-emitting nuclides ideal. If only a few $\alpha$ tracks traverse the nucleus DNA, double-strand breaks will be generated and force the cell into repair or apoptosis (33). Cells that manage to repair the double-strand breaks may lose their ability to survive or, more importantly, to divide and thus prevent metastatic growth. The growth inhibition studies performed point solidly to a dose-related effect that can easily be blocked by adding an excess of non-labelled antibody, which competes for the receptors. In the experiment, the cytotoxicity from antibodies in the media was non-detectable, but increased rapidly with dose as soon as a number of labelled antibodies could bind to the cell. The results (survival fraction of $5 \%$ to $10 \%$ after about 20 cell-associated decays) correspond well with data obtained by other researchers. Palm and coworkers reported that 35 astatine decays are required to obtain a surviving fraction of $37 \%$ Colo- 205 cells treated with astatinated C215 monoclonal antibody (34). The discrepancies between this result and ours may stem from the fact that C215 is a non-internalising antibody. This may cause the secondary $\alpha$ from the ${ }^{211}$ Po pathway to be lost due to a dissociation of the newly formed polonium daughter into the media, where the daughter of an astatine nuclide coupled to an internalising antibody might be trapped in the intracellular compartment (14).

An interesting phenomenon is an increase in the doubling time of surviving cells in 2 samples ( 1 of 3 cell dishes were devoid of cells, dividing or non-dividing). Among several explanations, we can speculate that the surviving cells belong to an initially radioresistant subclone, which is not normally manifested because of the small number of cells, or it might be that the cell-cycle control machinery slowed proliferation to provide time for the repair of DNA damage. Before implementing treatment, the overall toxicity to the patient must be considered. If the treatment is toxic and reduces the patient's quality of life, the benefits of treatment must be high enough to make the cost worthwhile. To make a first stage assessment of toxicity of the conjugate, a biodistribution in normal mice was performed, which showed no elevated uptake of astatine in comparison with iodine except in the thyroid and stomach. This elevated uptake points to a probable in vivo deastatination of the antibody conjugate, since free astatine is known to accumulate in the thyroid and stomach (35). Other studies using different antibodies revealed the same effect, which means it is not trastuzumab-related (26). Treatment with perchlorate could alleviate this problem (35), but if this was impossible, loss of thyroid function can be alleviated by modern medicine to a large extent and could be deemed as an acceptable side effect of tumour treatment in some cases. Blood levels of radioactivity were high, but the low cytotoxicity of non-targeted astatine, as demonstrated in the growth curve experiments, allows us to hope that myelotoxicity will be moderate. The differences in animal models, as well as data presentation, make it difficult to perform a strictly quantitative comparison of our biodistribution data with data from other studies on targeting ErbB2 $(29,32,36)$. However, a qualitative assessment shows that the use of halobenzoic acid for the labelling of antibody does not deteriorate its biodistribution in comparison with other methods. The uptake of trastuzumab in the liver and spleen seems to be somewhat elevated, but might be caused by the use of a humanized antibody in an immunocompetent murine model, which may effect a mouse anti-human antibody response.

In conclusion, the results of this study demonstrate that astatinated trastuzumab specifically binds ErbB2-expressing breast cancer cells with nanomolar affinity. In vitro experiments demonstrated a high and selective cytotoxicity. Besides elevated radioactivity uptake in the thyroid and stomach, no adverse effect of astatination on biodistribution was observed in comparison with radioiodination. These results encourage further research on the application of astatinated trastuzumab as a therapy for ErbB2-expressing tumours.

\section{Acknowledgements}

The authors would like to extend their gratitude to Anna Orlova for synthesis of SPMB, Veronica Asplund Eriksson for laboratory support, and Åsa Liljegren-Sundberg and Jörgen Carlsson for their advice on experimental planning. This work was supported by grants from the Swedish Cancer Society (nos. 4712-B02-01XAC and 3978-B03-07XBB). These experiments comply with current Swedish law. The animal experiment was performed with permission from the Uppsala Committee of Animal Research Ethics (permission C119/0).

\section{References}

1. WHO: World Health Report 2002. http://www.who.int/whr/ 2002/en/.

2. Goldenberg DM: Advancing role of radiolabeled antibodies in the therapy of cancer. Cancer Immunol Immunother 52: 281-296, 2003.

3. Yarden Y and Sliwkowski MX: Untangling the ErbB signalling network. Nat Rev Mol Cell Biol 2: 127-137, 2001.

4. Schiffer IB, Gebhard S, Heimerdinger CK, et al: Switching off HER-2/neu in a tetracycline-controlled mouse tumour model leads to apoptosis and tumour-size-dependent remission. Cancer Res 63: 7221-7231, 2003 .

5. Press MF, Cordon-Cardo C and Slamon DJ: Expression of the HER-2/neu proto-oncogene in normal human adult and fetal tissues. Oncogene 5: 953-962, 1990.

6. Natali PG, Nicotra MR, Bigotti A, et al: Expression of the p185 encoded by HER2 oncogene in normal and transformed human tissues. Int J Cancer 45: 457-461, 1990.

7. Ross JS and Fletcher JA: The HER-2/neu oncogene in breast cancer: prognostic factor, predictive factor, and target for therapy. Oncologist 3: 237-252, 1998.

8. Wester K, Sjostrom A, de la Torre M, Carlsson J and Malmstrom PU: HER-2 - a possible target for therapy of metastatic urinary bladder carcinoma. Acta Oncol 41: 282-288, 2002.

9. Burris HA 3rd: Docetaxel (Taxotere) plus trastuzumab (Herceptin) in breast cancer. Semin Oncol 28: 38-44, 2001.

10. Pegram MD: Docetaxel and herceptin: foundation for future strategies. Oncologist 6 (Suppl 3): 22-25, 2001.

11. Horton J: Trastuzumab use in breast cancer: clinical issues. Cancer Control 9: 499-507, 2002.

12. Sliwkowski MX, Lofgren JA, Lewis GD, Hotaling TE, Fendly BM and Fox JA: Nonclinical studies addressing the mechanism of action of trastuzumab (Herceptin). Semin Oncol 26: 60-70, 1999.

13. Horning SJ: Future directions in radioimmunotherapy for B-cell lymphoma. Semin Oncol 30: 29-34, 2003.

14. Zalutsky MR and Vaidyanathan G: Astatine-211-labeled radiotherapeutics: an emerging approach to targeted alpha-particle radiotherapy. Curr Pharm Des 6: 1433-1455, 2000. 
15. Vaidyanathan G and Zalutsky MR: Targeted therapy using alpha emitters. Phys Med Biol 41: 1915-1931, 1996.

16. Wilbur DS, Jones DS and Fritzberg AR: Synthesis and radioiodinations of some aryltin compounds for radiolabeling of monoclonal antibodies. J Labelled Compd Radiopharm 23: 1304-1306, 1986

17. Koziorowski J, Henssen C and Weinreich R: A new convenient route to radioiodinated $\mathrm{N}$-succinimidyl 3- and 4-iodobenzoate, two reagents for radioiodination of proteins. Appl Radiat Isot 49: 955-959, 1998.

18. Sjöström A, Tolmachev V, Lebeda O, Koziorowski J, Carlsson J and Lundqvist $\mathrm{H}$ : Direct astatination of a tumour-binding protein, human epidermal growth factor, using nido-carborane as a prosthetic group. J Radioanalytical Nucl Chem 256: 191-197, 2003.

19. Browne E and Firestone R: Table of Radioactive Isotopes. John Wiley and Sons, 1986.

20. Haigler HT, Maxfield FR, Willingham MC and Pastan I: Dansylcadaverine inhibits internalization of ${ }^{125}$ I-epidermal growth factor in BALB 3T3 cells. J Biol Chem 255: 1239-1241, 1980.

21. Lindmo T, Boven E, Cuttitta F, Fedorko J and Bunn PA Jr: Determination of the immunoreactive fraction of radiolabeled monoclonal antibodies by linear extrapolation to binding at infinite antigen excess. J Immunol Methods 72: 77-89, 1984.

22. Nias AH and Fox M: Minimum clone size for estimating normal reproductive capacity of cultured cells. Br J Radiol 41: 468-474, 1968.

23. Johansson L, Nilsson K, Carlsson J, Larsson B and Jakobsson P: Radiation effects on cultured human lymphoid cells. Analysis using the growth extrapolation method. Acta Radiol Oncol 20: 51-59, 1981.

24. Sundberg AL, Almqvist Y, Orlova A, et al: Combined effect of gefitinib ('Iressa', ZD1839) and targeted radiotherapy with ${ }^{211}$ At-EGF. Eur J Nucl Med Mol Imaging 30: 1348-1356, 2003.

25. Nazeer T, Ballouk F, Malfetano JH, Figge H and Ambros RA: Multivariate survival analysis of clinicopathologic features in surgical stage I endometrioid carcinoma including analysis of HER-2/neu expression. Am J Obstet Gynecol 173: 1829-1834, 1995.

26. Hadley SW, Wilbur DS, Gray MA and Atcher RW: Astatine211 labeling of an antimelanoma antibody and its Fab fragment using $\mathrm{N}$-succinimidyl $\mathrm{p}$-astatobenzoate: comparisons in vivo with the $\mathrm{p}-[125 \mathrm{I}]$ iodobenzoyl conjugate. Bioconjug Chem 2: 171-179, 1991.
27. Wilbur DS, Vessella RL, Stray JE, Goffe DK, Blouke KA and Atcher RW: Preparation and evaluation of para-[211At] astatobenzoyl labeled anti-renal cell carcinoma antibody $\mathrm{A} 6 \mathrm{H}$ $\mathrm{F}\left(\mathrm{ab}^{\prime}\right) 2$. In vivo distribution comparison with para-[125I] iodobenzoyl labeled A6H F(ab')2. Nucl Med Biol 20: 917-927, 1993.

28. Tsai SW, Sun Y, Williams LE, Raubitschek AA, Wu AM and Shively JE: Biodistribution and radioimmunotherapy of human breast cancer xenografts with radiometal-labeled DOTA conjugated anti-HER2/neu antibody 4D5. Bioconjug Chem 11: 327-334, 2000.

29. De Santes K, Slamon D, Anderson SK, et al: Radiolabeled antibody targeting of the HER-2/neu oncoprotein. Cancer Res 52: 1916-1923, 1992.

30. Larsen RH and Bruland OS: Radiolysis of radioimmunoconjugates. Reduction in antigen-binding ability by $\alpha$-particle radiation. J Labelled Comp Radiopharm 36: 1009-1018, 1995.

31. McDevitt MR, Finn RD, Ma D, Larson SM and Scheinberg DA: Preparation of alpha-emitting ${ }^{213} \mathrm{Bi}$-labeled antibody constructs for clinical use. J Nucl Med 40: 1722-1727, 1999.

32. Zalutsky MR, Xu FJ, Yu Y, et al: Radioiodinated antibody targeting of the HER-2/neu oncoprotein: effects of labeling method on cellular processing and tissue distribution. Nucl Med Biol 26: 781-790, 1999.

33. Palm S, Back T, Claesson I, et al: Effects of the alpha-particle emitter At-211 and low-dose-rate gamma-radiation on the human cell line Colo-205 as studied with a growth assay. Anticancer Res 18: 1671-1676, 1998.

34. Palm S, Back T, Claesson I, et al: Single-cell irradiation from [211At] astatine-labeled C215 monoclonal antibody: improved estimates of radiosensitivity from measurements on cellular uptake and retention. Anticancer Res 23: 1219-1221, 2003.

35. Larsen RH, Slade S and Zalutsky MR: Blocking [211At]astatide accumulation in normal tissues: preliminary evaluation of seven potential compounds. Nucl Med Biol 25: 351-357, 1998.

36. Xu FJ, Yu YH, Bae DS, et al: Radioiodinated antibody targeting of the HER-2/neu oncoprotein. Nucl Med Biol 24: 451-459, 1997. 